\title{
New research directions on disparities in obesity and type 2 diabetes
}

Pamela L. Thornton, ${ }^{1}$ Shiriki K. Kumanyika, ${ }^{2}$ Edward W. Gregg, ${ }^{3}$ Maria R. Araneta, ${ }^{4}$ Monica L. Baskin, ${ }^{5}$ Marshall H. Chin, ${ }^{6}$ Carlos J. Crespo, ${ }^{7}$ Mary de Groot,${ }^{8}$ David O. Garcia, ${ }^{9}$ Debra HaireJoshu, ${ }^{10}$ Michele Heisler, ${ }^{11}$ Felicia Hill-Briggs, ${ }^{12}$ Joseph A. Ladapo,${ }^{13}$ Nangel M. Lindberg, ${ }^{14}$ Spero M. Manson, ${ }^{15}$ David G. Marrero, ${ }^{16}$ Monica E. Peek, ${ }^{17}$ Alexandra E. Shields, ${ }^{18}$ Deborah F. Tate, ${ }^{19}$ and Carol M.Mangione ${ }^{20}$

1. Division of Diabetes, Endocrinology, and Metabolic Diseases; National Institute of Diabetes and Digestive and Kidney Diseases (NIDDK), National Institutes of Health, Bethesda, MD.

2. Drexel Uniyersity Dornsife School of Public Health, Philadelphia, PA.

3. Epidemiology and Statistics Branch, Division of Diabetes Translation, Centers for Disease Control and Prevention (CDC), Atlanta, GA. Current Affiliation: Imperial College London, School of Public Health, Epidemiology and Biostatistics, South Kensington Campus, London, UK.

4. University of California San Diego Department of Family Medicine and Public Health, La Jolla, CA.

5. University of Alabama at Birmingham Department of Medicine Division of Preventive Medicine, Birmingham, AL.

6. University of Chicago Medicine, Chicago.

7. Oregon Health and Science University and Portland State University joint School of Public Health, Portland, OR.

8. Indiana University School of Medicine, Indianapolis, IN.

9. University of Arizona Mel and Enid Zuckerman College of Public Health, Department of Health Promotion Sciences, Tucson, AZ.

10. Washington University in St. Louis, School of Medicine and The Brown School, St. Louis, MO.

11. University of Michigan Medical School, Ann Arbor, MI.

12. Johns Hopkins School of Medicine and Welch Center for Prevention, Epidemiology \& Clinical Research, Baltimore, MD.

13. David Geffen School of Medicine at the University of California, Los Angeles, Los Angeles, CA.

14. Kaiser Permanente Center for Health Research, Portland, OR.

15. Colorado School of Public Health, Aurora, CO.

16. University of Arizona Health Sciences, Phoenix, AZ.

17. University of Chicago Medicine, Chicago, IL.

18. Harvard/MGH Center on Genomics, Vulnerable Populations, and Health Disparities, Mongan Institute, Mass. General Hospital and Department of Medicine, Harvard Medical School, Boston, MA.

19. University of North Carolina Gillings School of Global Public Health, Chapel Hill, NC.

20. David Geffen School of Medicine at the University of California, and UCLA Fielding School of Public Health, Los Angeles, Los Angeles, CA.

Corresponding Author: Pamela L. Thornton, Ph.D., M.S.W., Division of Diabetes, Endocrinology, and Metabolic Diseases, National Institute of Diabetes and Digestive and Kidney Diseases, National Institutes of Health, 6707 Democracy Blvd, Bethesda, Maryland 20892-5460

Email: pamela.thornton@nih.gov

This is the author manuscript accepted for publication and has undergone full peer review but has not been through the copyediting, typesetting, pagination and proofreading process, which may lead to differences between this version and the Version of Record. Please cite this article as doi:

10.1111/nyas.14270.

This article is protected by copyright. All rights reserved. 


\begin{abstract}
Obesity and type 2 diabetes disproportionately impact U.S. racial and ethnic minority communities and low-income populations. Improvements in implementing efficacious interventions to reduce the incidence of type 2 diabetes are underway (i.e., National Diabetes Prevention Program), but challenges in effectively scaling-up successful interventions and reaching at-risk populations remain. In October 2017, the National Institutes of Health's National Institute of Diabetes and Digestive and Kidney Diseases, National Cancer Institute, and Office of Disease Prevention convened a workshop to understand: (1) how to address socioeconomic and other environmental conditions that perpetuate disparities in the burden of obesity and type 2 diabetes; (2) how to design effective prevention and treatment strategies that are accessible, feasible, culturally-relevant, and acceptable to diverse population groups; and (3) how to achieve sustainable health improvement approaches in communities with the greatest burden of these diseases. Common features of guiding frameworks to understand and address disparities and promote health equity were described. Promising research directions were identified in numerous areas, including study design, methodology, and core metrics; program implementation and scalability; the integration of medical care and social services; strategies to enhance patient empowerment; and understanding and addressing the impact of psychosocial stress on disease onset and progression in addition to factors that support resiliency and health.
\end{abstract}

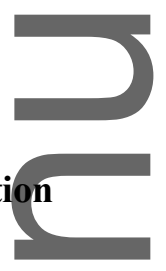

Obesity and type 2 diabetes are national epidemics that disproportionately impact certain populations in the United-States (i.e., disparity populations). Specifically, Alaska Native, American Indian, Asian American, Native Hawaiian and Pacific Islander, non-Hispanic Black, and Hispanic adults bear a disproportionate burden of illness related to these conditions compared to non-Hispanic Whites, ${ }^{1,2}$ as do those with low socioeconomic status, living in rural areas, and identifying as LGBTQ. ${ }^{3}$ Large efficacy trials have demonstrated that lifestyle change and/or medication (i.e., metformin) can prevent or delay progression of prediabetes to type 2 diabetes. $^{4}$

Efforts to scale-up and spread efficacious interventions are underway (e.g., National Diabetes Prevention Program), ${ }^{5}$ but our knowledge of evidence-based strategies that specifically reduce diabetes-related disparities is limited. Innovative approaches, including strategies to improve available interventions and promote their long-term, wide-spread implementation among those at greatest risk are needed. A central challenge in improving population health is translating research conducted under the best case scenarios of well-resourced randomized controlled trials into real world scenarios, which requires addressing environmental, economic, and social factors that affect individuals' engagement in and response to these interventions. ${ }^{6}$

This article is protected by copyright. All rights reserved. 


\section{Workshop overview}

The workshop entitled Enhancing Opportunities in Addressing Obesity and Type 2 Diabetes पintios,

Disparities, was convened at the National Institutes of Health (NIH) in Bethesda, Maryland on October $24=27,2017$ to inform research opportunities for reducing disparities in these two conditions.

The workshøp was co-sponsored by the National Institute of Diabetes and Digestive and Kidney

Diseases (NIDDK), the National Cancer Institute (NCI), and the NIH Office of Disease Prevention (ODP), and organized in coordination with representatives of six NIH Institutes/Offices. ${ }^{a}$ Opening remarks by Dr. Griffin Rodgers, the NIDDK Director, and Dr. Eliseo Pérez-Stable, Director of the National Institute on Minority Health and Health Disparities (NIMHD), emphasized the importance of the workshop in identifying focal points for the next generation of high impact studies designed to reduce disparities in the burden of obesity and diabetes through elucidating the social contextual mechanisms of disease etiology, and facilitating lifestyle behavior changes, healthcare system interventions, and partnered community-based programs. Many questions remain, including how best to (1) address the secioeconomic and other environmental influences that have historically and currently affect the same minority populations and under-resourced and rural communities that bear a disproportionate burden of illness; (2) design prevention and treatment strategies to be accessible, feasible, culturally-relevant, and acceptable to at-risk communities; and (3) achieve sustainable health improvement strategies in communities that have the greatest burden of these chronic diseases.

More than 80 participants attended the workshop, including academic researchers and healthcare leaders with expertise in epidemiology, healthcare systems, primary care, behavioral interventions, public health, cultural adaptation of interventions, behavioral economics, health policy and administration, and implementation science. During the 2-day workshop, expert presentations facilitated rigorous discussion and helped identify promising research directions.

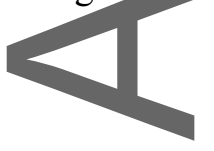

\footnotetext{
${ }^{a}$ National Institute of Diabetes and Digestive and Kidney Diseases, the National Cancer Institute, the Office of Disease Prevention, Office of the NIH Director, National Heart, Lung, and Blood Institute, National Institute on Minority Health and Health Disparities, Office of Behavioral and Social Sciences Research, Office of the NIH Director.
}

This article is protected by copyright. All rights reserved. 


\section{Epidemiologic overview}

Epidemiological trends illustrate how the obesity and diabetes epidemics have grown in recent decades and the consequent adverse impact on population health. Figure 1 shows marked disparities in diabetes prevalence by race/ethnicity, education, and income. ${ }^{7}$ Prevalence of diagnosed and undiagnosed diabetes is highest in non-Hispanic Black and Mexican American adults and notably higher in all three ethnic groups when compared to Whites. Based on Indian Health Service data, the prevalence of diagnosed diabetes among Indians/Alaska Natives is $15 \%$, higher than in the other ethnic minority populations. ${ }^{8}$

Figure 1 also shows the inverse gradients in diabetes prevalence with education and poverty. Figure 2 depicts striking geographic variations in diabetes and obesity prevalence. Evidence indicates that area level poverty is the strongest single predictor of being a high-risk county. ${ }^{9}$ The specific factors explaining why high poverty counties are at such excess risk, and what works to reduce this risk, need to be elucidated. In under-resourced communities, the importance of neighborhood context recint as a constraint on access to resources and options for healthy eating and active living has been welldocumented, 10,11,12 yet we lack sufficient surveillance data to adequately identify modifiable risk factors in the highest risk neighborhoods.

The effects of education, income, and other indices of socioeconomic status (SES) among people with or at risk for diabetes are often mediated by behavioral risk factors, including dietary patterns, levels of physical activity, and smoking. ${ }^{13}$ For example, Siegel et al. ${ }^{10}$ reported that, in a nationally-representative survey, higher education was associated with meeting diet-related diabetes prevention goals for intake of vegetables, whole grains, meats, and healthy oils. Lower SES has historically been associated with worse glycemic control among adults with type 2 diabetes, particularly younger adults. ${ }^{14,15}$ Quality of diabetes care and preventive care practices to forestall diabetes-related complications vary according to disparities in access to care. ${ }^{16}$ For example, even among insured populations, Latinos are less likely to receive regular care and less likely to meet 
HbA1c targets. ${ }^{17,18}$ Lack of access to care in non-Hispanic Blacks is also associated with not meeting blood pressure targets. ${ }^{19}$

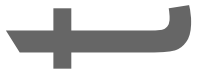

Although there have been encouraging reductions in most diabetes complications in the United States, with some improvements across all affected groups, disparities remain. They are observed most clearly in non-Hispanic Blacks, who have substantially higher rates of end-stage renal disease (ESRD), amputation, and stroke, ${ }^{20}$ and in Hispanics and Asian Americans who have elevated ESRD complications. ${ }^{21,22}$ Within these groups, men have notably higher rates of lower extremity amputation and myocardial infarction than women. The pattern of disparities in complications according to markers of social class and education does not appear to be consistent.

There have been successes in reducing diabetes-related complications through improvements in medical technology and care, cardiovascular risk factor management and glycemic control, selfmanagement, and policy approaches (e.g., policy changes that have decreased smoking rates or improved access to health insurance and care). ${ }^{23,24}$ Yet, there has been little success in reducing disparities. Reducing the disparities gap in diabetes and obesity incidence and outcomes requires tackling the social and environmental influences (e.g., neighborhood poverty, access to quality care, psychosocial stressors) known to affect disease etiology and exacerbate disparities. Diverse methods for assessing the effectiveness of interventions to reduce disparities and increase knowledge regarding the pathways and mechanisms through which social disadvantage translates into increased risk of disease are also needed.

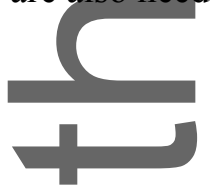

\section{Definitions and guiding frameworks}

The concepts of health equity and social determinants of health (SDoH) were central to the workshop dialogue. According to the World Health Organization, “'Health equity' or 'equity in health' implies that ideally everyone should have a fair opportunity to attain their full health potential and that no one should be disadvantaged from achieving this potential." 25 Improving health equity is a stated national 
priority and is inextricably linked to the goal of eliminating health disparities. ${ }^{26}$ The concept of equity involves "the absence of avoidable, unfair, or remediable differences among groups of people, whether those groups are defined socially, economically, demographically or geographically or by other means of stratification". ${ }^{25}$ A large body of research demonstrates that such public health goals cannot be realized without addressing the underlying SDoH, which include environmental, economic, and social factors that significantly contribute to disparities and thus warrant much more attention. ${ }^{27}$

Several frameworks useful for understanding and addressing health disparities and health equity issues in obesity and diabetes prevention and care were presented. These included a novel healthcare and community systems-oriented model for assessing policy and social/environmental factors influencing health equity, informed by joint analyses of health equity issues affecting ethnic minority populations in the United States and Aotearoa/New Zealand. ${ }^{28}$ This model depicts the way government and private policies impact the healthcare system, the integration of healthcare system and social services, and the relevant $\mathrm{SDoH}$, and consequently health equity (e.g., related to race/ethnicity, SES or socioeconomic deprivation) - all set within a larger context of history, culture, (2) and values. Other notable models discussed for conceptualizing health equity issues included: the Robert Wood Johnson Foundation's "Finding Answers" framework; ${ }^{29}$ the Getting to Equity in Obesity Prevention research and action framework; $;{ }^{30}$ the Three-Axis Model of Health Inequity; ${ }^{31}$ the Consolidated Framework for Implementation Research; ${ }^{32}$ and behavioral change models involving beliefs, knowledge, social norms, environmental factors, and self-efficacy, and intrinsic and extrinsic motivation 33,34 The NIMHD Research Framework ${ }^{35}$ along with the Patient-Centered Outcomes Research Institute (PCORI) perspectives were also featured as valuable resources that illustrate agencies' strategic priorities.

A theme that emerged from these presentations is that, despite sharing common features among health equity frameworks, there is value in having different frameworks for guidance within the policy, practice, and community contexts relevant to prevention and treatment. Some frameworks are designed to explain causes of disparities while others are designed to show where and how solutions to disparities could and should focus. Most frameworks-including those that focus 
primarily on healthcare delivery systems - acknowledge the importance of community contexts as key health determinants. Other common features among the frameworks were:

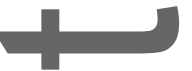

1. prominent recognition of the fundamental roles of race, ethnicity, SES, gender, and geography in determining health; and

2. emphasis on the need to tailor conceptual frameworks according to different health domains and contextual levels.

For example, with respect to the latter, causes rooted in inequitable social structures or inadequate social protections suggest high-level policy solutions, whereas causes related to risky behaviors may point to policy-oriented and individually or family-oriented interventions and the proximal contextual factors influencing these behaviors. Causes of inequities rooted in healthcare system processes could trigger solutions involving regulatory or financing agencies, institutions involved in provider training, and system-level policy mandates addressing ongoing provider training and quality improvement. Regardless, virtually all frameworks emphasize the need for mutually reinforcing interventions at multiple levels, through socioecological models using the traditional concentric circles or other formats, to represent interrelationships among individual, community, neighborhood and/or healthcare- and policy-level influences.

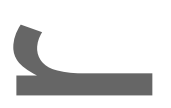

\section{Bridging interventions in healthcare settings to broader community contexts}

Interventions in healthcare settings to address obesity and type 2 diabetes-related disparities involve complex considerations at the patient-, provider-, healthcare system and policy-levels. Novel (1)

implementation approaches that take account of individuals' social context are necessary for full and sustained achievement of healthy lifestyle behaviors. Although a clinical perspective is considered foundational for diabetes treatment, the traditional clinical context is too narrow to accommodate broader influences on health disparities. 
Research agencies, such as PCORI, have shown a growing interest in simultaneously improving healthcare systems and addressing health disparities. Healthcare system interventions designed primarily for populations who face relatively few barriers to accessing care or adhering to medical recommendations may be less effective or even totally ineffective when implemented for patient populations whose access to care and barriers to participation are more challenging. Barriers to quality care and better outcomes that have been documented in the literature include: high and increasing out-of-pocket costs; time or distance factors or lack of transportation which limit access to care; absence of zoning laws and other policies that prevent exposure to adverse neighborhood conditions; unmet social needs; lack of language access, low health literacy, or cultural factors that influence communication; and implicit or explicit racial/ethnic or other biases among healthcare providers, other staff, or other healthcare system issues. ${ }^{36-40}$

The many ways that unmet social needs influence the effectiveness of treatments was a key workshop theme. As healthcare systems move toward value-based purchasing, models such as accountable care organizations and sharing of costs and savings with payors have increased incentives to address patients' health-related social needs, or unmet basic needs, to improve patient outcomes. Several of the frameworks discussed suggest ways to remove barriers and mitigate the adverse effects of social needs on treatment effectiveness. Medical interventions that consider social context and patients' social risk profiles to inform care or directly intervene on SDoH should also consider patient empowerment strategies. Shared-decision making (SDM) or informed care, wherein patients participate as full partners in the medical encounter and select a medical option that suits their values and priorities, was deemed critical. Shared-decision making improves outcomes such as patient satisfaction and maintaining treatment regimens; however, certain at-risk groups, such as African Americans, experience SDM less often than Whites, ${ }^{41}$ which may exacerbate health disparities. A workshop presentation exemplifies how the integration of medical and social care can improve patient outcomes (see Box 1). ${ }^{34,42-54}$ 
A sound business case is a critical step for supporting the adoption, dissemination, and spread of promising interventions, yet this aspect of interventions is rarely addressed in research. Analyses of costs, who bears them, and who benefits from the investment are recommended to promote sustained investments by payors and avoid the discontinuation of high-value effective interventions, as observed in previousprevention efforts. ${ }^{55}$ Without an equity lens, most current payment mechanisms do not support or incentivize the provision of tailored care approaches necessary to reduce disparities. A key factor is the period in which the return on investment (ROI) is expected. Private insurers or agencies with clients that incur high costs may fear losing them before ROI occurs. For example, there is potential for loss of ROI because of relocations, job and insurance changes, or temporal gaps in coverage due to lack of affordability or strict health insurance eligibility criteria.

\section{Addressing social determinants in community and neighborhood contexts}

Workshop participants discussed research on three types of interventions to address social determinants of health in community and neighborhood contexts. Two types represent compensatory interventions that provide supports that enable individuals to fill gaps and access otherwise inaccessible or unavailable resources to overcome influences of negative $\mathrm{SDoH} .{ }^{6}$ The third type concerns root cause $e^{27,56}$ oriented interventions designed to change underlying structures/systems rather than compensate for them.

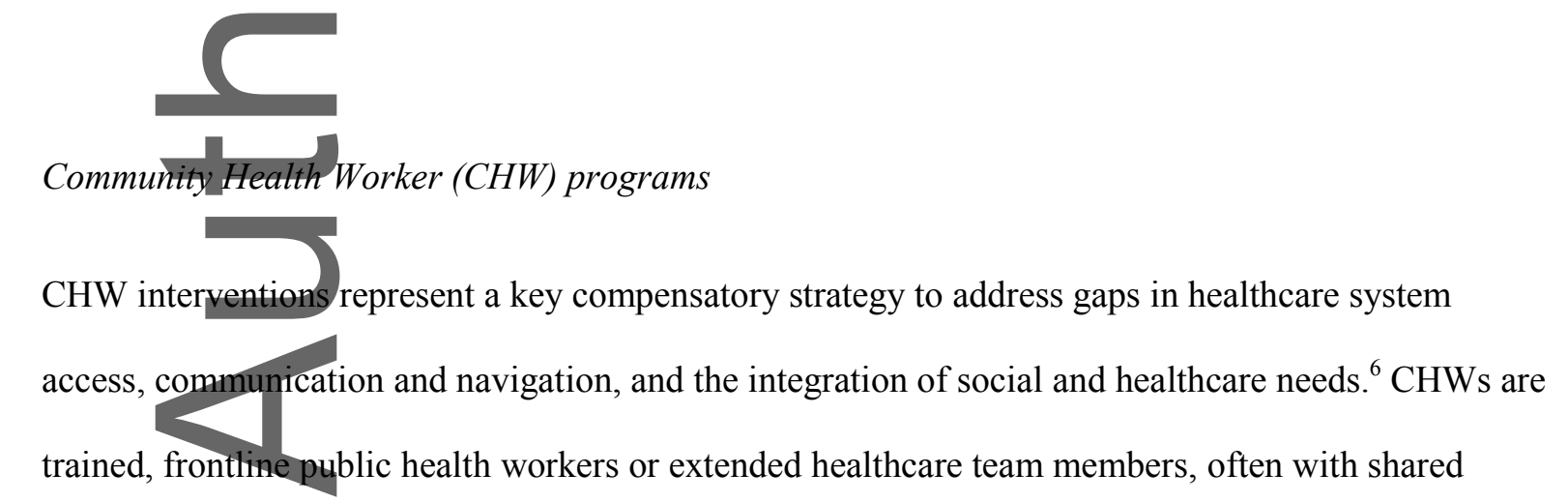

This article is protected by copyright. All rights reserved. 
characteristics (community, culture, language) as their clients (individuals or families). ${ }^{b}$ They

typically garner trust and provide cultural mediation among community members, healthcare systems, and social services; and deliver culturally relevant and accessible program content, informal

counseling, coaching, and advocacy for clients to ensure their needs are met. ${ }^{57-59}$ Models of care vary, as CHWs may work alone or as part of delivery teams to conduct a range of activities effective for preventing and managing chronic diseases, promoting use of primary care and follow-up care, reducing unnecessary utilization, and providing outreach, and navigation to social and community services. ${ }^{60} \mathrm{CHWS}$ and lay persons who complete training as Diabetes Prevention Program (DPP) Lifestyle Coaehes for diabetes prevention are being tested on a national scale for effectiveness in achieving DPP-related lifestyle change and behavioral outcomes among people at increased risk for type 2 diabetes. ${ }^{61}$ Interventions engaging CHWs can improve glycemic control and weight-related outcomes among people at increased risk for type 2 diabetes, be cost effective, and thus are deemed to play an important role in reducing health disparities, improving minority health, and enhancing health equity when implemented in under-resourced communities. ${ }^{60}$

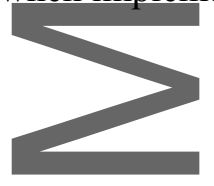

Remotely delivered Intervention formats

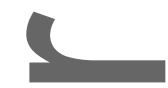

The increasing use of internet, mobile phones/smart phones, and social media in the highly digitized economy of the 21 st century has enabled tests of remotely delivered approaches to expand reach of and access to effective prevention and treatment programs. The potential convenience and enhanced options for people with limited access, including some in racial/ethnic minority populations, lowincome populations and rural populations, ${ }^{62}$ foreshadow substantial gains for prevention and treatment. The literature on effectiveness of remotely delivered approaches to treat obesity is promising, but the effects specific to minority populations are understudied. A systematic review of eHealth interventions for weight management shows interventions for the prevention and treatment of

\footnotetext{
${ }^{b}$ Community Health Workers are also known by a variety of names, including community health aide, promotora/promotores de salud, patient navigator.
}

This article is protected by copyright. All rights reserved. 
adult obesity have generally been effective compared to usual care or controls but with modest weight losses. ${ }^{63}$ Few studies have $50 \%$ or more subjects from racial or ethnic minority groups or outcomes reported by race. ${ }^{63}$ Subsequent studies have demonstrated the acceptability and feasibility of remotely delivered obesity programs and suggest strategies to enhance recruitment of African Americans and Hispanics. ${ }^{64}$ A trial with predominantly Hispanic women participating in the Special Supplemental Nutrition Program for Women, Infants, and Children (WIC) program found that an internet-based weight loss program in addition to WIC resulted in significantly greater weight loss over 12 months compared to the WIC program alone. ${ }^{65}$

Intervening on neighborhood contexts

Physical, or built, environments can profoundly shape health and health behaviors related to eating and physical activity. Relevant interventions include: making improvements to physical infrastruetures (safe/walkable neighborhoods, recreational facilities, convenient transportation choices, access to healthy foods), and complementary policy and messaging strategies. Such strategies require a systems approach, with coordinated action by multiple sectors and disciplines (e.g., communitystakeholders, economists, urban and regional planners, social scientists) within and outside of the biomedical-behavioral fields. Moving to Opportunity, a randomized social experiment, offers convincing evidence of the impact of one's neighborhood environment on diabetes and obesity. ${ }^{66}$ Neighborhood change was effected by affording women with children the opportunity to move from a neighborhood with high poverty rates to a neighborhood with lower poverty rates. Moving was associated with lower obesity and diabetes biomarkers and reductions in extreme prevalence of obesity and diabetes. ${ }^{66}$

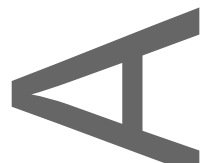

\section{Improving community engagement and cultural relevance}

Efforts to maximize effectiveness of interventions targeting obesity and diabetes in racial/ethnic minority, rural or other under-resourced communities further underscore the significance of social 
context and cultural relevance. Presenters discussed their experiences working with Black Americans, Hispanic Americans, Asian Americans, and American Indians and Alaska Natives (AI/AN).

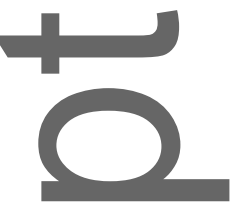

Theoretical and conceptual frameworks

Two complementary cultural adaptation frameworks are widely used in this arena. Resnicow et al. differentiate between adaptations of surface or deep structure. ${ }^{67}$ Surface structure adaptions are relatively superficial, such as, matching intervention components to observable characteristics of the population group of interest, while deep structure adaptations incorporate elements of the relevant core values and key cultural practices of community members. ${ }^{67}$ Kreuter et al describe five specific types of cultural tailoring: peripheral tailoring is similar to Resnicow's surface structure; evidential refers to using data showing relevance of the problem; linguistic refers to using the preferred language(s). constituent involving approaches base adaptations on information obtained through direct engagement with members of the population of interest; and sociocultural-similar to deep structure-incorporates relevant core values and sociocultural perspectives and other health determinants. ${ }^{68}$ Examples from The Special Diabetes Program for Indians underscores the anthropological perspective on culture, i.e., deep structure. Culturally-influenced explanatory models of illness and how symptoms are interpreted may differ markedly from the views of health providers, ${ }^{69}$ which was an implicit or explicit theme across many workshop presentations.

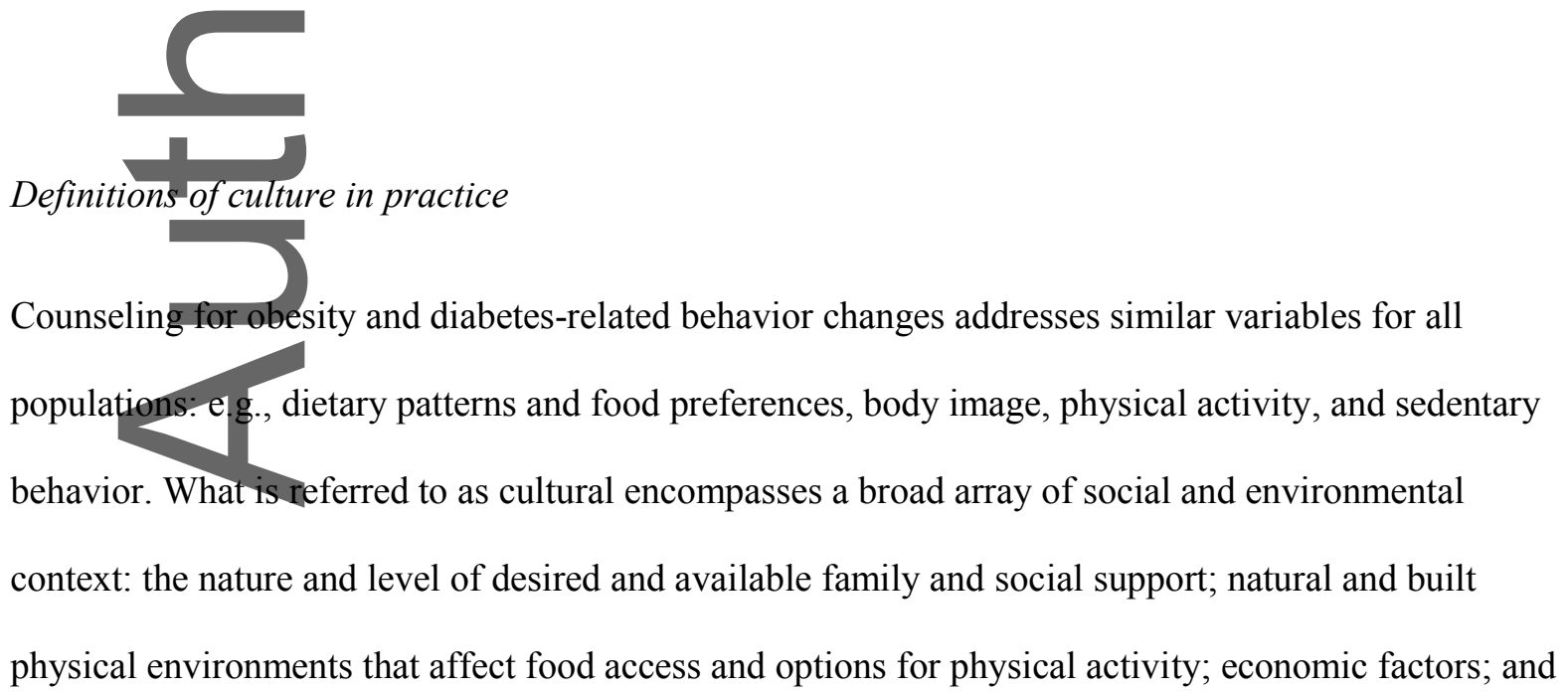

This article is protected by copyright. All rights reserved. 
various logistical challenges that influence whether people can achieve the intended level of intervention attendance. At any given level of motivation, these factors shape or interact with healthrelated knowledge, norms, values, and beliefs to influence behavior or behavior change. Thus, cultural adaptations must consider ways to help people navigate challenges they encounter in attempting to following recommendations for weight loss or diabetes self-management during and after a program. A common theme was that effective interventions must be grounded in a deep understanding of both culture and contextual variables, both how these variables interact with each other and how they affect individuals and communities. Intersections among various influences were also stressed. For example, understanding how obesity and diabetes management in Black women in the Deep South (e.g., rural Alabama and Mississippi) may be influenced not only by race and gender, but also by regional, rural, and economic factors..$^{70,71}$

For Asian Americans, the definition of obesity itself is problematic. Current guidelines and practice lead to underdiagnosis of obesity among Asian Americans by clinicians and national surveys. Obesity as assessed by body mass index (BMI) may lead Asian Americans to also underestimate their obesity-related risks. Diabetes prevalence in Asian Americans is higher than would be expected based on their average BMI levels, and is more similar to that in Black and Hispanic Americans than in Whites (Fig. 1). ${ }^{72}$

BMI is particularly inadequate for reflecting risks related to body fatness and body fat distribution in diverse Asian American populations. If risk is not recognized, there is insufficient triggering of preventive and treatment interventions. In 2015, the American Diabetes Association revised the BMI eut point for diabetes screening among Asian Americans to BMI $\geq 23 \mathrm{~kg} / \mathrm{m}^{2} .73$ Awareness and implementation of these revised guidelines among clinicians and Asian American communities have not been evaluated, but reinforces the need to adapt health messaging to the culture of Asian Americans. ${ }^{73,74}$

For example, Filipino Americans with normal BMI have significantly more visceral adipose tissue (by computed tomography) compared to clinically obese African Americans, ${ }^{75}$ while South 
Asians have excess hepatic fat accumulation. ${ }^{76}$ Differences in diabetes prevalence among Asian American subgroups emphasize the importance of disaggregating Asian American subgroups; diabetes prevalence in California was highest among Pacific Islanders, Filipinos, and South Asians (from India, Pakistan, Bangladesh, Sri Lanka) compared to groups often perceived to be at highest risk for diabetes, including non-Hispanic Blacks, Hispanics and Native Americans. ${ }^{77}$ Diabetes risk was 50\% higher among Southeast Asians, Japanese, Vietnamese, Koreans, and Chinese Americans compared to White populations, with onset of diabetes occurring at lower BMI levels. ${ }^{77}$ Understanding the unique pathophysiology of type 2 diabetes, including regional fat distribution, in specific Asian American communities, is urgently needed to inform effective interventions in this rapidly growing population. Raising awareness of body composition and metabolic profiles in subgroups of Asian Americans is also needed to improve interventions aimed at reducing diabetes within these communities.

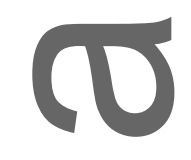

\section{Success stories and promising approaches}

While culturally and contextually adapted interventions constitute a relatively small portion of the evidence base regarding obesity and diabetes interventions, all presenters provided evidence of successful approaches. For example, the potential value and practicality of using individuallytailored, small changes approaches to prevent excess weight gain in Black women was noted. ${ }^{78}$ Among Hispanic women, pre-intervention educational approaches that provide basic information on diabetes, food measurement or nutrition facilitate intervention uptake and improve success in behavioral weight loss programs. ${ }^{79}$

Because of its scope and special features, the Special Diabetes Program for Indians was highlighted as an exemplar of cultural and contextual adaptations. The successes of this program attest to the value of: having a year-long process for strategic planning and increasing community readiness; building upon cultural strengths and traditions; incorporating family in the intervention 
process; emphasizing collective as well as individual support; and ongoing reinforcement of core principles for success among families, providers, and in the community at large..$^{80} 81$

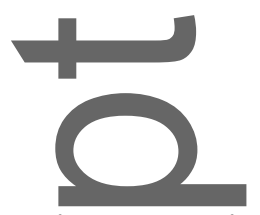

\section{Psychosocial and socioecological stress as an emerging theme}

Increasingly, epidemiological research investigating factors associated with risk of chronic diseases such as diabetes and obesity is focusing on understanding the underlying biological pathways or mechanisms through which social disadvantage "gets under the skin" to increase risk of disease, thus potentially identifying new leverage points for intervention. The importance of identifying biomarkers to elucidate mechanisms through which stressors increase risk of disease was also presented. Psychosocialstress, which includes diverse stressors at the individual and community levels (e.g., physical and sexual abuse, neighborhood-level poverty, work stress, discrimination), has been shown to increase individuals' risk of many chronic diseases. For example, self-reported experiences of discrimination has been associated with increased visceral fat in women, ${ }^{82}$ and increased risk of type 2 diabetes independent of obesity or behavioral and psychosocial factors. ${ }^{83}$ Stress at work and home, financial stress, depression, and perceived ability to control life circumstances have been associated with increased risk of acute myocardial infarction. ${ }^{84}$ Because certain psychosocial stressors (e.g., exposure to violence, social position, trauma) are disproportionately experienced by poor and minority communities in the U.S. ${ }^{85}$ investigating the underlying mechanisms through which such stressors operate to increase risk of disease is a critical piece of the puzzle in eliminating disparities in the burden of illness. ${ }^{86}$

Dysregulation of the stress pathway is one way in which adverse psychosocial exposures becomes embodied. Human experiments show that both emotional and physical stressors trigger the central stress response and neuroendocrine systems, which can result in a cascade of hormonal changes linked to increased risk of obesity, metabolic syndrome, and poor glycemic control. ${ }^{87}$ While animal models have illuminated some of the key mechanisms at play, it is impossible to use these to model the diverse stressors faced by humans. Key variables for future studies include inherited and 
acquired personal characteristics (e.g., physiology/genetic, personality type, past trauma, perceptions of the stress) and characteristics of the stressor (e.g., severity, duration, frequency). DNA methylation provides a valuable platform for investigating the impact of various psychosocial stressors on risk of disease. Altered DNA methylation in HPA axis (i.e., stress-related) genes has been associated with increased risk of hypertension, certain cancers, and post-traumatic stress disorders. ${ }^{88}$ Telomere length is another valuable biomarker for exploring the role of psychosocial stress in disease. Telomeres contribute to cell senescence and longevity, and measures of psychosocial stress have been associated with accelerated telomere shortening. ${ }^{89}$

Research is also beginning to focus on positive psychosocial factors thought to support resiliency and health. Mind-body stress-reduction interventions such as the Relaxation Response Resiliency (3RP) Program or meditation, for example, have been shown to enhance expression of genes associated with favorable energy metabolism, insulin secretion, and telomere maintenance $;^{90,91}$ and suggest a positive benefit for cardiovascular health and reducing blood glucose levels. ${ }^{92,93}$ Religion and spirittality have emerged as potentially important sources of resiliency for minority and low-income communities, ${ }^{94}$ and may be particularly important for African American and Hispanic/Latino communities who report higher levels of religious and spiritual beliefs and practices than White and Asian American populations. ${ }^{95}$ In a recent national study of African American women in the United States; for example, those who used religion or spirituality to cope with stress were significantly less likely to develop hypertension, and this protective effect was greater among those with the highest levels of perceived stress. ${ }^{96}$ The same impact of religious coping on risk of hypertension was not found in a national sample of White women. ${ }^{97}$ Social support has also been shown to buffer the adverse effects of stress on one's health, with evidence from randomized controlled trials and experimental studies showing that various facets of social support improve diabetes control ( $\mathrm{HbA1c}$ ) and diabetes-related physical activity, weight loss, and quality of life. ${ }^{98-100}$

Evidence in the areas of socioecological and psychosocial stress is long-standing and provides emerging opportunities to improve obesity and diabetes prevention and treatment. Future challenges include modeling the complexity of these interactions as well as determining any differences in This article is protected by copyright. All rights reserved. 
patterns of stress across and within different racial/ethnic and socioeconomic populations. Equally important are studies investigating positive resources for resiliency, which may help identify and prioritize additional areas for intervention. Ultimately, there is a need to identify and better understand effective strategies to minimize the adverse effects of psychosocial stress on diabetes and obesity outcomes and remove, where possible, the adverse stressors that disproportionately impact minority and other underserved populations.

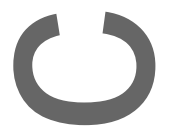

Frameworks for understanding mental health and diabetes distress

Mental health conditions such as depression and diabetes-related distress are known risk factors for obesity and type 2 diabetes. ${ }^{101}$ Depression can induce neuroendocrine reactivity and metabolic consequences resulting in obesity and type 2 diabetes. ${ }^{87,102}$ Evidence from epidemiological studies show that depression is both a risk factor for diabetes as well as a comorbid condition of diabetes. Depression is up to twice as common among individuals with diabetes compared to those without the condition; ${ }^{103,104}$ and has consistently been associated with higher risk of diabetes complications, ${ }^{105}$ poorer quality of life, ${ }^{106}$ and increased risk of mortality. ${ }^{107,} 108$ Pharmacological treatments such as antidepressant use are associated with risk of incident type 2 diabetes among adults ${ }^{102,109,110}$ and youth; ${ }^{111}$ and use of antipsychotic drugs is associated with high fasting blood glucose, diabetic ketoacidosis, and hyperglycemic death. ${ }^{102,109-111}$ Additionally, cultural misunderstandings and clinician bias have resulted in prescribing more and higher doses of antipsychotic medications to African Americans compared to Whites, possibly without awareness of the potential higher sensitivity of some African Americans to certain psychotropic medication, causing more severe side effects (e.g., delirium). ${ }^{112}$ Clinicians are cautioned to avoid under or overtreatment for mental health conditions by examining patient-specific drug sensitivities and by taking cultural factors into account. Given the potential for adverse side effects of drugs used to treat mental illness and evidence that culture and ethnic factors influence provider bias, ${ }^{112}$ the studies of appropriate prescribing and diagnostic accuracy are urgent research needs.

This article is protected by copyright. All rights reserved. 
Diabetes-related distress, another psychosocial condition, refers to unique often hidden "emotional distress in diabetes that emphasizes the demanding experience of diabetes and requires diabetes-specific measurement and treatment approaches" (p. 236) ${ }^{113}$ and "the spectrum of patient experience when managing a severe, demanding chronic disease like diabetes" (p. 259). ${ }^{114}$ Diabetes distress is considered common and persistent over time, ${ }^{114}$ with higher rates among ethnic diverse patients than non-Hispanic Whites. ${ }^{115}$ Diabetes-related distress is associated with diabetes self-care and elevated $\mathrm{HbAl}$, which in turn increases the risk for the development of diabetes complications, ${ }^{116,117}$ but this consideration may not be reflected in current healthcare practice.

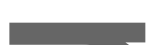

\section{Research translation: challenges and opportunities}

A cross-cutting discussion focused on the central challenges of moving from efficacy studies (i.e., the best-case scenarios that provide convincing evidence of what can work) to demonstrating effectiveness in terms of what works in diverse and particularly under-resourced communities. A

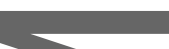
concern - and frustration - related to repeated observations that research findings from efficacy studies are not reaching populations at large, especially higher risk populations, in ways that fulfill the promise inherent in this research ${ }^{118}$ was frequently voiced by workshop participants. The relevance of models typically used in efficacy studies to effectiveness research in real-world settings was questioned based on differences in both participant and intervention characteristics. Workshop participants' views on this problem echoed several themes from the discussion about community engagement and cultural relevance as well as other sessions, framing the issues as contrasts between efficacy and effectiveness research. Overall, workshop participants emphasized that better translation science and efforts are needed, and this reflects a broader concern in the field. ${ }^{118}$

Population characteristics and circumstances

Even when participants from high-risk populations are included in efficacy studies, the screening and selection into these studies achieve a certain level of homogeneity on variables related to the ability to participate. Because unbiased interpretation of efficacy trials requires achievement of the intended 
intervention dose and high participant retention, extraordinary measures may be taken to mitigate circumstances that constrain the necessary level and quality of participation. In contrast, recognizing and allowing for heterogeneity on variables such as cultural perspectives, attitudes and behaviors, and socioeconomic circumstances, neighborhoods, built environments and resources (transportation, etc.) among these population groups become critical in community-based research if the research findings are to be meaningful in practice. Factors related to healthcare access, delivery patterns and out-ofpocket costs must be considered inasmuch as they determine the context for adoption and maintenance of health behavior changes. The rise of high deductible health plans and limited benefits have decreased the affordability of healthcare especially for employed persons with limited incomes. ${ }^{119}$ For people who are not U.S. citizens, immigration-related factors related to employment or fear of deportation may be an important overlay influencing program participation or use of healthcare. ${ }^{120}$ These factors, if not recognized or understood, can lead to inappropriate assumptions, e.g., that low motivation, rather than practical issues or preferences, is the main reason for lower participation rates or suboptimal behavioral outcomes.

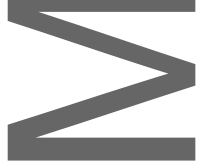

Intervention characteristics

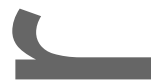

The time and logistical demands of attending a series of classes or counseling sessions can be prohibitive, particularly given competing demands on time or other practical constraints as noted above. Possible ways to address this include data collection to better understand these constraints, combined with testing more flexible ways of delivering interventions. A distinction was made between achieving flexibility versus reducing participant burden by limiting the dose (e.g., minimal models for lifestyle intervention). The content or frequency needed to achieve the optimal effect of interventions is not always clear. One approach that might increase the feasibility and sustainability of interventions would be linking them to ongoing, community services (e.g., linking to commercial weight loss programs which are more consumer or client oriented, and sustainable, than researcherdesigned approaches). One example is the aforementioned remote intervention linked to WIC ${ }^{65}$ that 
embeds interventions in federal or state-funded programs which reach low-income populations to expand dissemination efforts across diverse populations in settings that are integral to people's daily lives. Box 2 highlights an example of linking nutrition and physical activity counseling to services provided by a national parent support organization. ${ }^{121-123}$ Such approaches may allow for the needed dose of interventions to be achieved over a longer period, or intermittently, compared to the typical approach of providing a high, front-end dose within a concentrated period.

Additionally, greater use of telephone or digital technology to deliver or tailor interventions ${ }^{64}$ was discussed as having a high potential because many high-risk populations are heavy users of webor cell-technologies. ${ }^{124}$ However, limitations on broadband access were noted as a potential issue to be resolved for rural populations. ${ }^{125}$

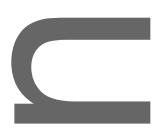

\section{Conclusion}

Promising researeh directions to address obesity and type 2 diabetes disparities consider at the person, community/neighborhood-, and system-levels, and are guided by frameworks to promote health equity (see Table 1). Translating lifestyle interventions for diverse communities requires research to demonstrate the effectiveness of interventions that are affordable, accessible, convenient, and sensitive to socioecological contexts, and offer equitable access to these interventions. The adoption of health equity approaches in intervention design (e.g., engagement and recruitment, implementation strategies) are needed. The ultimate goal of investments in this research would be to promote individuals engagement in evidenced-based interventions and help population groups reduce exposure to or overcome the effects of practical and stress-related challenges in their physical, sociocultural, and economic environments.

Intervening on the SDoH can improve health inequity by removing systemic barriers, thereby addressing root causes of obesity and diabetes-related disparities, and helping individuals overcome contextual challenges related to prevention and self-care. Novel research approaches could account for community realities and resources and treat neighborhoods as focal points for intervening on the compelling geographic variations in health. Implementation efforts can also leverage national and This article is protected by copyright. All rights reserved. 
state-wide programs to expand reach of evidence-based interventions to diverse communities and intergenerational households. Importantly, high-impact research opportunities that leverage health equity approaches may identify ways to interrupt the intergenerational consequences of obesity and diabetes; and more effectively treat individual, families and communities that are currently affected to support reaching their highest health potential.

\section{Acknowledgements}

The authors of this manuscript provided substantial contributions to its conception by submitting workshop presentations and data described in the manuscript. They also participated in the major revisions of the manuscript's intellectual content and approved the final version of the submitted manuscript, P.L. Thornton and S. Kumanyika designed the manuscript and developed the initial draft; E. Gregg co-drafted the epidemiology section; A. Shields co-drafted the psychosocial/socioecological stress section; M. Peek and M. Chin drafted Box 1; D. Haire-Joshu drafted Box 2. All authors contributed to the revision of Table 1. Additional substantial contributions to the development of this manuscript were made by Dr. Joseph Selby who provided scientific presentations and contributed to rigorous participant deliberations at the workshop that informed Table 1. M. Austin Argentieri affiliated with the Harvard/MGH Center on Genomics, Vulnerable Populations, and Health Disparities assisted with co-editing the psychosocial/socioecological stress section and technical editing.

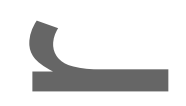

The authors wish to acknowledge the contributions of the trans-NIH workshop planning committee to the workshop program; and the National Cancer Institute Division of Cancer Control and Population Sciences and the NIH Office of Disease Prevention for co-sponsoring the workshop with travel support for presenters.

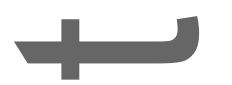

The authors also acknowledge and appreciate contributions of Dr. Griffin Rodgers, Director of the NIDDK and Dr. Eliseo Pérez-Stable, Director of the NIMHD, for their presentations to set the tone of the workshop deliberations.

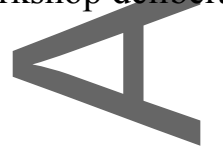

\section{Competing interests and funding}

Dr. Chin: Grant funding from NIDDK (National Chicago Center for Diabetes Translation Research, P30 DK092949), the Robert Wood Johnson Foundation Advancing Health Equity: Leading Care, 
Payment, and Systems Transformation Program Office, and the Merck Foundation Bridging the Gap: Reducing Disparities in Diabetes Care National Program Office. He is a consultant to the PatientCentered Outcomes Research Institute and a member of the National Advisory Council to the National Institute on Minority Health and Health Disparities.

Dr. De Groot: Faculty consultant to the Lifescan Diabetes Institute and Eli Lilly, Co.

Dr. Haire-Joshu: Grant funding from NIDDK (Washington University Center for Diabetes Translation Research, P30DK092950; R01DK121475-01) and NHLBI (R01HL143360-01); Centene Corporation (Center for Health Transformation, Faculty Director) outside the submitted the work.

Dr. Kumanyika: Grant funding from NIDDK (Washington University Center for Diabetes Translation Research, P30DK092950, Disparities Core).

Dr. Mangione: Member of the U.S. Preventive Services Task Force. This article does not necessarily represent the views and policies of the U.S. Preventive Services Task Force.

Dr. Peek: Grant funding from NIDDK (National Chicago Center for Diabetes Translation Research, P30 DK092949); and the Merck Foundation (2017-2022) for the National Program Officed "Bridging the Gap: Reducing Disparities in Diabetes Care"

Dr. Manson: Grant funding from NIDDK (Center for American Indian and Alaska Native Diabetes Translation Research, P30 DK092923)

Dr. Shields: Grant funding from the John Templeton Foundation (Grant \#48424 and \#59607)

Dr. Tate: Member of the WW Scientific Advisory Board.

\section{Disclaimer}

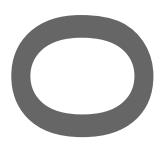

The findings and conclusions in this report are those of the authors and do not necessarily represent the official position of the National Institutes of Health, the National Institute of Diabetes and Digestive and Kidney Diseases, or any other institution mentioned in the manuscript.

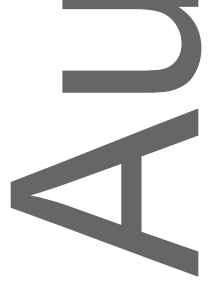

This article is protected by copyright. All rights reserved. 


\section{References}

1. Bullard, K.M., C.C. Cowie, S.E. Lessem, et al. 2018. Prevalence of Diagnosed Diabetes in Adults by Diabetes Type - United States, 2016. MMWR Morb Mortal Wkly Rep. 67: 359-361.

2. Ogden, GL., T.H. Fakhouri, M.D. Carroll, et al. 2017. Prevalence of Obesity Among Adults, by Household Income and Education - United States, 2011-2014. MMWR Morb Mortal Wkly Rep. 66: 1369-1373.

3. Dilley, J.A., K.W. Simmons, M.J. Boysun, et al. 2010. Demonstrating the importance and feasibility of including sexual orientation in public health surveys: health disparities in the Pacific Northwest. Am J Public Health. 100: 460-467.

4. Knowler, W.C., E. Barrett-Connor, S.E. Fowler, et al. 2002. Reduction in the incidence of type 2 diabetes with lifestyle intervention or metformin. N Engl J Med. 346: 393-403.

5. U.S. Department of Health and Human Services. Centers for Disease Control and Prevention. 2018. National Diabetes Prevention Program Accessed January 10, 2018.

https://www.cdc.gov/diabetes/prevention/index.html.

6. Haire-Joshu, D. \& F. Hill-Briggs. 2019. The Next Generation of Diabetes Translation: A Path to Health Equity. Annu Rev Public Health.

7. Gregg, E. 2019. 'Prevalence of Total Diabetes (Diagnosed Diabetes and Undiagnosed Diabetes) in the U.S. Adult Population, Age $\geq 20,2011-2016$ (PIR=Poverty Income Ratio)' unpublished data, National Health and Nutrition Examination Survey.

8. Centers for Disease Control and Prevention. (Centers for Disease Control and Prevention, U.S. Dept of Health and Human Services; 2017.). National Diabetes Statistics Report, 2017. Atlanta, GA.

9. Cunningham, S.A., S.A. Patel, G.L. Beckles, et al. 2018. County-level contextual factors associated with diabetes incidence in the United States. Ann Epidemiol. 28: 20-25 e22.

10. Siegel, K.R., K.M. Bullard, G. Imperatore, et al. 2018. Prevalence of Major Behavioral Risk Factors for Type 2 Diabetes. Diabetes Care. 41: 1032-1039.

11. Lovasi, G.S., M.A. Hutson, M. Guerra, et al. 2009. Built environments and obesity in disadvantaged populations. Epidemiol Rev. 31: 7-20.

12. Nelson, M.C., N.I. Larson, D. Barr-Anderson, et al. 2009. Disparities in dietary intake, meal patterning, and home food environments among young adult nonstudents and 2- and 4-year college students. Am J Public Health. 99: 1216-1219.

13. Petrovic, D., C. de Mestral, M. Bochud, et al. 2018. The contribution of health behaviors to socioeconomic inequalities in health: A systematic review. Prev Med. 113: 15-31.

14. Bijlsma-Rutte, A., F. Rutters, P.J.M. Elders, et al. 2018. Socio-economic status and HbA1c in type 2 diabetes: A systematic review and meta-analysis. Diabetes/metabolism research and reviews. 34: e3008.

15. Ali,M.K.,K. McKeever Bullard, G. Imperatore, et al. 2012. Characteristics associated with poor glycemic control among adults with self-reported diagnosed diabetes--National Health and Nutrition Examination Survey, United States, 2007-2010. MMWR Suppl. 61: 32-37.

16. Mayberry, L.S., E.M. Bergner, R.J. Chakkalakal, et al. 2016. Self-Care Disparities Among Adults with Type 2 Diabetes in the USA. Curr Diab Rep. 16: 113.

17. Brown, A.F., R.B. Gerzoff, A.J. Karter, et al. 2003. Health behaviors and quality of care among Latinos with diabetes in managed care. Am J Public Health. 93: 1694-1698.

18. Mosen, D.M., A. Feldstein \& A. Borin. 2015. Disparities in Glycemic Control Among Hispanic Adults with Diabetes Journal of Patient-Centered Research and Reviews. 2: 114-.

19. Muntner, P., M. Abdalla, A. Correa, et al. 2017. Hypertension in Blacks: Unanswered Questions and Future Directions for the JHS (Jackson Heart Study). Hypertension. 69: 761-769.

20. Gregg, E.W., Y. Li, J. Wang, et al. 2014. Changes in diabetes-related complications in the United States, 1990-2010. N Engl J Med.370: 1514-1523.

21. Desai, N., C.M. Lora, J.P. Lash, et al. 2019. CKD and ESRD in US Hispanics. Am J Kidney Dis. 73: 102-111.

This article is protected by copyright. All rights reserved. 
22. Zheng, Y., S.H. Ley \& F.B. Hu. 2018. Global aetiology and epidemiology of type 2 diabetes mellitus and its complications. Nat Rev Endocrinol. 14: 88-98.

23. Ford, E.S., U.A. Ajani, J.B. Croft, et al. 2007. Explaining the decrease in U.S. deaths from coronary disease, 1980-2000. N Engl J Med. 356: 2388-2398.

24. Ali, M.K., K.M. Bullard \& E.W. Gregg. 2013. Achievement of goals in U.S. Diabetes Care, 1999-2010. NEngl J Med. 369: 287-288.

25. World Health Organization. 2019. Health Equity. Accessed May 27, 2019.

https://www.who.int/topics/health_equity/en/.

26. U.S. Department of Health and Human Services. Office of Disease Prevention and Health Promotion.2019, March 20. Healthy People 2020. https://www.healthypeople.gov/.

27. Marmot, M. 2005. Social determinants of health inequalities. Lancet. 365: 1099-1104.

28. Chin, MIH. P.T. King, R.G. Jones, et al. 2018. Lessons for achieving health equity comparing Aotearoa/New Zealand and the United States. Health Policy. 122: 837-853.

29. Chin, M.H., A.R. Clarke, R.S. Nocon, et al. 2012. A roadmap and best practices for organizations to reduce racial and ethnic disparities in health care. J Gen Intern Med. 27: 992-1000.

30. Kumanyika. S. 2017. Getting to Equity in Obesity Prevention: A New Framework. 2017, January 18. Aecessed 2018, January 3, 2018. https://nam.edu/getting-to-equity-in-obesity-preventiona-new-framework/.

31. Tung, E.L,, K.A. Cagney, M.E. Peek, et al. 2017. Spatial Context and Health Inequity: Reconfiguring Race, Place, and Poverty. J Urban Health. 94: 757-763.

32. Damsehroder, L.J., D.C. Aron, R.E. Keith, et al. 2009. Fostering implementation of health services research findings into practice: a consolidated framework for advancing implementation science. Implement Sci. 4: 50.

33. Kao, A.C. 2015. Driven to Care: Aligning External Motivators with Intrinsic Motivation. Health Serv Res. 50 Suppl 2: 2216-2222.

34. Peek, M.E. M.J. Ferguson, T.P. Roberson, et al. 2014. Putting theory into practice: a case study of diabetes-related behavioral change interventions on Chicago's South Side. Health Promot Pract. 15:-40S-50S.

35. U.S. Department of Health and Human Services, N.I.o.H., National Institute on Minority Health and Health Disparities, . 2018. NIMHD Minority Health and Health Disparities Research Framework. Accessed January 3, 2018. https://www.nimhd.nih.gov/about/overview/researchframework/.

36. Alley, D.E., C.N. Asomugha, P.H. Conway, et al. 2016. Accountable Health Communities-Addressing Social Needs through Medicare and Medicaid. N Engl J Med. 374: 8-11.

37. Cooper, L.A., D.L. Roter, K.A. Carson, et al. 2012. The associations of clinicians' implicit attitudes about race with medical visit communication and patient ratings of interpersonal care. $\mathrm{Am} J$ Public Health. 102: 979-987.

38. Ben, J., D. Cormack, R. Harris, et al. 2017. Racism and health service utilisation: A systematic review and meta-analysis. PLoS One. 12: e0189900.

39. Bervick, D.M., T.W. Nolan \& J. Whittington. 2008. The triple aim: care, health, and cost. Health Aff (Millwood). 27: 759-769.

40. Chen, A.H., M.K. Youdelman \& J. Brooks. 2007. The legal framework for language access in healthcare settings: Title VI and beyond. J Gen Intern Med. 22 Suppl 2: 362-367.

41. Peek, M.E. A. Odoms-Young, M.T. Quinn, et al. 2010. Race and shared decision-making: perspectives of African-Americans with diabetes. Soc Sci Med. 71: 1-9.

42. Wilkes, A.E., K. Bordenave, L. Vinci, et al. 2011. Addressing diabetes racial and ethnic disparities: lessons learned from quality improvement collaboratives. Diabetes Manag (Lond). 1: 653660.

43. Peek,M.E., A.E. Wilkes, T.S. Roberson, et al. 2012. Early lessons from an initiative on Chicago's South Side to reduce disparities in diabetes care and outcomes. Health Aff (Millwood). 31: 177-186.

44. Peek, M.E., S.A. Harmon, S.J. Scott, et al. 2012. Culturally tailoring patient education and communication skills training to empower African-Americans with diabetes. Transl Behav Med. 2: 296-308.

This article is protected by copyright. All rights reserved. 
45. Nundy, S., J.J. Dick, M.C. Solomon, et al. 2013. Developing a behavioral model for mobile phone-based diabetes interventions. Patient Educ Couns. 90: 125-132.

46. Nundy, S., C.Y. Lu, P. Hogan, et al. 2014. Using Patient-Generated Health Data From Mobile Technologies for Diabetes Self-Management Support: Provider Perspectives From an Academic Medical Center. JDiabetes Sci Technol. 8: 74-82.

47. Goddu, A.P., T.S. Roberson, K.E. Raffel, et al. 2015. Food Rx: a community-university partnership to prescribe healthy eating on the South Side of Chicago. J Prev Interv Community. 43: 148-162.

48. Nundy, S., J.J. Dick, A.P. Goddu, et al. 2012. Using mobile health to support the chronic care model: developing an institutional initiative. Int J Telemed Appl. 2012: 871925.

49. Peek, M.E., M. Ferguson, N. Bergeron, et al. 2014. Integrated community-healthcare diabetes interventions to reduce disparities. Curr Diab Rep. 14: 467.

50. Chin, M.H., A.P. Goddu, M.J. Ferguson, et al. 2014. Expanding and sustaining integrated health care-community efforts to reduce diabetes disparities. Health Promot Pract. 15: 29S-39S.

51. Goddu, A.P., K.E. Raffel \& M.E. Peek. 2015. A story of change: The influence of narrative on African-Americans with diabetes. Patient Educ Couns. 98: 1017-1024.

52. Nundy, S., A. Mishra, P. Hogan, et al. 2014. How do mobile phone diabetes programs drive behavior change? Evidence from a mixed methods observational cohort study. Diabetes Educ. 40: 806-819.

53. Nundy, S., J.J. Dick, C.H. Chou, et al. 2014. Mobile phone diabetes project led to improved glycemic control and net savings for Chicago plan participants. Health Aff (Millwood). 33: 265-272. 54. Chin, M.H. \& D. Goldmann. 2011. Meaningful disparities reduction through research and translation programs. JAMA. 305: 404-405.

55. Leatherman, S., D. Berwick, D. Iles, et al. 2003. The business case for quality: case studies and an analysis. Health Aff (Millwood). 22: 17-30.

56. Marmot, M. \& H. Commission on Social Determinants of. 2007. Achieving health equity: from root causes to fair outcomes. Lancet. 370: 1153-1163.

57. Kim, K., J.S. Choi, E. Choi, et al. 2016. Effects of Community-Based Health Worker Interventions to Improve Chronic Disease Management and Care Among Vulnerable Populations: A Systematic Review. Am J Public Health. 106: e3-e28.

58. Gary, T.L.,M. Batts-Turner, L.R. Bone, et al. 2004. A randomized controlled trial of the effects of nurse case manager and community health worker team interventions in urban AfricanAmericans with type 2 diabetes. Control Clin Trials. 25: 53-66.

59. Gary, T.L., M. Batts-Turner, H.C. Yeh, et al. 2009. The effects of a nurse case manager and a community health worker team on diabetic control, emergency department visits, and hospitalizations among urban African Americans with type 2 diabetes mellitus: a randomized controlled trial. Arch Intern Med. 169: 1788-1794.

60. U.S. Department of Health and Human Services. Centers for Disease Control and Prevention. Community Preventive Services Task Force. 2017. Diabetes Prevention: Interventions Engaging Community Health Workers: A Systematic Review. Accessed January 10, 2018.

https://www.thecommunityguide.org/findings/diabetes-prevention-interventions-engagingcommunity-health-workers.

61. U.S. Department of Health and Human Services. Centers for Disease Control and Prevention. 2018, March 1. Centers for Disease Control and Prevention Diabetes Prevention Recognition Program: Standards and Operating Procedures. Accessed January 20, 2019, 2018. https://www.cdc.gov/diabetes/prevention/pdf/dprp-standards.pdf.

62. Cho, Y.M., S. Lee, S.M.S. Islam, et al. 2018. Theories Applied to m-Health Interventions for Behavior Change in Low- and Middle-Income Countries: A Systematic Review. Telemed J E Health. 24: 727-741.

63. Bennett, G.G., D.M. Steinberg, C. Stoute, et al. 2014. Electronic health (eHealth) interventions for weight management among racial/ethnic minority adults: a systematic review. Obes Rev. 15 Suppl 4: 146-158.

This article is protected by copyright. All rights reserved. 
64. Tate, D.F., C.G. Valle, M.M. Crane, et al. 2017. Randomized trial comparing group size of periodic in-person sessions in a remotely delivered weight loss intervention. Int J Behav Nutr Phys Act. 14: 144.

65. Phelan, S., T. Hagobian, A. Brannen, et al. 2017. Effect of an Internet-Based Program on Weight Loss for Low-Income Postpartum Women: A Randomized Clinical Trial. JAMA. 317: 23812391.

66. Ludwig, J, L. Sanbonmatsu, L. Gennetian, et al. 2011. Neighborhoods, obesity, and diabetes-a randomized social experiment. $N$ Engl J Med. 365: 1509-1519.

67. Resnicow, K., T. Baranowski, J.S. Ahluwalia, et al. 1999. Cultural sensitivity in public health: defined and demystified. Ethn Dis. 9: 10-21.

68. Kreuter, M.W., S.N. Lukwago, R.D. Bucholtz, et al. 2003. Achieving cultural appropriateness in health promotion programs: targeted and tailored approaches. Health Educ Behav. 30: 133-146.

69. Allan, D. \& D. Cornes. 1998. The impact of management of change projects on practice: a description of the contribution that one educational programme made to the quality of health care. $J$ Adv Nurs. 27, 865-869.

70. Shikany, J.M., T.L. Carson, C.M. Hardy, et al. 2018. Assessment of the nutrition environment in rural counties in the Deep South. J Nutr Sci. 7: e27.

71. Ard, J.D., T.L. Carson, J.M. Shikany, et al. 2017. Weight loss and improved metabolic outcomes amongst rural African American women in the Deep South: six-month outcomes from a community-based randomized trial. J Intern Med. 282: 102-113.

72. Menke, A., S. Casagrande, L. Geiss, et al. 2015. Prevalence of and Trends in Diabetes Among Adults in the United States, 1988-2012. JAMA. 314: 1021-1029.

73. American Diabetes, A. 2015. (2) Classification and diagnosis of diabetes. Diabetes Care. 38

Suppl: S8-S16.

74. Hsu, W.C., M.R. Araneta, A.M. Kanaya, et al. 2015. BMI cut points to identify at-risk Asian Americans for type 2 diabetes screening. Diabetes Care. 38: 150-158.

75. Araneta, M.R. \& E. Barrett-Connor. 2005. Ethnic differences in visceral adipose tissue and type 2 diabetes: Filipino, African-American, and white women. Obes Res. 13: 1458-1465.

76. Shah, A.D. N.R. Kandula, F. Lin, et al. 2016. Less favorable body composition and adipokines in South Asians compared with other US ethnic groups: results from the MASALA and MESA studies. Int J Obes (Lond). 40: 639-645.

77. Karter, A.J., D. Schillinger, A.S. Adams, et al. 2013. Elevated rates of diabetes in Pacific Islanders and Asian subgroups: The Diabetes Study of Northern California (DISTANCE). Diabetes Care. 36: $574-579$

78. Phillips, E.G., M.T. Wells, G. Winston, et al. 2017. Innovative approaches to weight loss in a high-risk population: The small changes and lasting effects (SCALE) trial. Obesity (Silver Spring). 25: $833-841$

79. Lindberg, N.M., V.J. Stevens, S. Vega-Lopez, et al. 2012. A weight-loss intervention program designed for Mexican-American women: cultural adaptations and results. J Immigr Minor Health. 14: 1030-1039.

80. Jiang, L., S.M. Manson, J. Beals, et al. 2013. Translating the Diabetes Prevention Program into American Indian and Alaska Native communities: results from the Special Diabetes Program for Indians Diabetes Prevention demonstration project. Diabetes Care. 36: 2027-2034.

81. Jiang, L., A. Johnson, K. Pratte, et al. 2018. Long-term Outcomes of Lifestyle Intervention to Prevent Diabetes in American Indian and Alaska Native Communities: The Special Diabetes Program for Indians Diabetes Prevention Program. Diabetes Care. 41: 1462-1470.

82. Lewis, T.T., H.M. Kravitz, I. Janssen, et al. 2011. Self-reported experiences of discrimination and visceral fat in middle-aged African-American and Caucasian women. Am J Epidemiol. 173: 12231231.

83. Whitaker, K.M., S.A. Everson-Rose, J.S. Pankow, et al. 2017. Experiences of Discrimination and Incident Type 2 Diabetes Mellitus: The Multi-Ethnic Study of Atherosclerosis (MESA). Am J Epidemiol. 186: 445-455.

This article is protected by copyright. All rights reserved. 
84. Rosengren, A., S. Hawken, S. Ounpuu, et al. 2004. Association of psychosocial risk factors with risk of acute myocardial infarction in 11119 cases and 13648 controls from 52 countries (the INTERHEART study): case-control study. Lancet. 364: 953-962.

85. American Psychological Association APA Working Group on Stress and Health Disparities. 2017. Stress and Health Disparities Report: Contexts, Mechanisms, and Interventions Among Racial/Ethnic Minority and Low Socioeconomic Status Populations. https://www.apa.org/pi/healthdisparities/resources/stress-report.

86. Shrelds, A.E. 2017. Epigenetic signals of how social disadvantage "gets under the skin": a challenge to the public health community. Epigenomics. 9: 223-229.

87. Brotman, D.J., S.H. Golden \& I.S. Wittstein. 2007. The cardiovascular toll of stress. Lancet. 370: $1089-1100$.

88. Argentieri, M.A., S. Nagarajan, B. Seddighzadeh, et al. 2017. Epigenetic Pathways in Human Disease: The Impact of DNA Methylation on Stress-Related Pathogenesis and Current Challenges in Biomarker Development. EBioMedicine. 18: 327-350.

89. Epel, E.S. E.H. Blackburn, J. Lin, et al. 2004. Accelerated telomere shortening in response to life stress. Proc Natl Acad Sci U S A. 101: 17312-17315.

90. Bhasin, M.K., J.A. Dusek, B.H. Chang, et al. 2013. Relaxation response induces temporal transcriptome changes in energy metabolism, insulin secretion and inflammatory pathways. PLoS One. 8: e62817.

91. Dusek, J.A., H.H. Otu, A.L. Wohlhueter, et al. 2008. Genomic counter-stress changes induced by the relaxation response. PLoS One. 3: e2576.

92. Levine, G.N., R.A. Lange, C.N. Bairey-Merz, et al. 2017. Meditation and Cardiovascular Risk Reduction: A Scientific Statement From the American Heart Association. J Am Heart Assoc. 6. 93. Ray, I.B., A.R. Menezes, P. Malur, et al. 2014. Meditation and coronary heart disease: a review of the current clinical evidence. Ochsner J. 14: 696-703.

94. VanderWeele, T.J., J. Yu, Y.C. Cozier, et al. 2017. Attendance at Religious Services, Prayer, Religious Coping, and Religious/Spiritual Identity as Predictors of All-Cause Mortality in the Black Women's Health Study. Am J Epidemiol. 185: 515-522.

95. Pew Research Center. 2014. Religious Landscape Study.

https://www.pewforum.org/religious-landscape-study/.

96. Cozier, Y.C., J. Yu, L.A. Wise, et al. 2018. Religious and Spiritual Coping and Risk of Incident Hypertension in the Black Women's Health Study. Ann Behav Med. 52: 989-998.

97. Spence, N., M. Farvid, E. Warner, et al. 2019 [in press]. Religious Service Attendance, Religious Coping, and Risk of Hypertension in Women Participating in the Nurses' Health Study II. American Journal of Epidemiology.

98. van Dam, H.A., F.G. van der Horst, L. Knoops, et al. 2005. Social support in diabetes: a systematic review of controlled intervention studies. Patient Educ Couns. 59: 1-12.

99. Cohen, S. 2004. Social relationships and health. Am Psychol. 59: 676-684.

100. Berkman, L.F., T. Glass, I. Brissette, et al. 2000. From social integration to health: Durkheim in the new millennium. Soc Sci Med. 51: 843-857.

101. Young-Hyman, D., M. de Groot, F. Hill-Briggs, et al. 2016. Psychosocial Care for People With Diabetes: A Position Statement of the American Diabetes Association. Diabetes Care. 39: 21262140 .

102. Noordam, R., N. Aarts, R.P. Peeters, et al. 2016. Selective Serotonin Reuptake Inhibitors Decrease Pancreatic Insulin Secretion in Older Adults and Increase the Risk of Insulin Dependence in Type 2 Diabetes Patients. J Clin Psychiatry. 77: e1124-e1129.

103. Anderson, R.J., K.E. Freedland, R.E. Clouse, et al. 2001. The prevalence of comorbid depression in adults with diabetes: a meta-analysis. Diabetes Care. 24: 1069-1078.

104. Ali, S., M.A. Stone, J.L. Peters, et al. 2006. The prevalence of co-morbid depression in adults with Type 2 diabetes: a systematic review and meta-analysis. Diabet Med. 23: 1165-1173.

105. de Groot, M., R. Anderson, K.E. Freedland, et al. 2001. Association of depression and diabetes complications: a meta-analysis. Psychosom Med. 63: 619-630.

106. Goldney, R.D., P.J. Phillips, L.J. Fisher, et al. 2004. Diabetes, depression, and quality of life: a population study. Diabetes Care. 27: 1066-1070.

This article is protected by copyright. All rights reserved. 
107. Katon, W.J., C. Rutter, G. Simon, et al. 2005. The association of comorbid depression with mortality in patients with type 2 diabetes. Diabetes Care. 28: 2668-2672.

108. Zhang, X., S.L. Norris, E.W. Gregg, et al. 2005. Depressive symptoms and mortality among persons with and without diabetes. Am J Epidemiol. 161: 652-660.

109. Rubin, R.R., Y. Ma, M. Peyrot, et al. 2010. Antidepressant medicine use and risk of developing diabetes during the diabetes prevention program and diabetes prevention program outcomes study. Diabetes Care. 33: 2549-2551.

110. Andersohn, F., R. Schade, S. Suissa, et al. 2009. Long-term use of antidepressants for depressive disorders and the risk of diabetes mellitus. Am J Psychiatry. 166: 591-598.

111. Burcu, M., J.M. Zito, D.J. Safer, et al. 2017. Concomitant Use of Atypical Antipsychotics With Other Psychotropic Medication Classes and the Risk of Type 2 Diabetes Mellitus. J Am Acad Child Adolesc Psychiatry. 56: 642-651.

112. News and Notes. 2001. US Surgeon General releases report on mental health: culture, race, and ethnicity. Public Health Rep. 116: 376.

113. Gonzalez, J.S., L. Fisher \& W.H. Polonsky. 2011. Depression in diabetes: have we been missing something important? Diabetes Care. 34: 236-239.

114. Fisher, L., D.M. Hessler, W.H. Polonsky, et al. 2012. When is diabetes distress clinically meaningful?: establishing cut points for the Diabetes Distress Scale. Diabetes Care. 35: 259-264.

115. Naranjo, D. D.M. Hessler, R. Deol, et al. 2012. Health and psychosocial outcomes in U.S. adult patients with diabetes from diverse ethnicities. Curr Diab Rep. 12: 729-738.

116. Hilliard, M.E., J.P. Yi-Frazier, D. Hessler, et al. 2016. Stress and A1c Among People with Diabetes Across the Lifespan. Curr Diab Rep. 16: 67.

117. Fisher, L., M.M. Skaff, J.T. Mullan, et al. 2007. Clinical depression versus distress among patients with type 2 diabetes: not just a question of semantics. Diabetes Care. 30: 542-548.

118. Koh, H.K., S.C. Oppenheimer, S.B. Massin-Short, et al. 2010. Translating research evidence into practice to reduce health disparities: a social determinants approach. Am J Public Health. 100

Suppl 1: S72-80.

119. Wharam, J.F., F. Zhang, E.M. Eggleston, et al. 2018. Effect of High-Deductible Insurance on High-Acuity Outcomes in Diabetes: A Natural Experiment for Translation in Diabetes (NEXT-D)

Study. Diabetes Care. 41: 940-948.

120. National Academies of Sciences, E. \& Medicine. 2018. Immigration as a Social Determinant of Health: Proceedings of a Workshop. The National Academies Press. Washington, DC.

121. Haire-Joshu, D., C.D. Schwarz, K. Steger-May, et al. 2018. A Randomized Trial of Weight Change in a National Home Visiting Program. Am J Prev Med. 54: 341-351.

122. Cahill, A.G., D. Haire-Joshu, W.T. Cade, et al. 2018. Weight Control Program and Gestational Weight Gain in Disadvantaged Women with Overweight or Obesity: A Randomized Clinical Trial. Obesity (Silver Spring). 26: 485-491.

123. Haire-Joshu, D., A.G. Cahill, R.I. Stein, et al. 2019. Randomized Controlled Trial of HomeBased Lifestyle Therapy on Postpartum Weight in Underserved Women with Overweight or Obesity. Obesity (Silver Spring). 27: 535-541.

124. Pew Research Center. 2019, June 12. Mobile Fact Sheet Accessed July 30, 2019.

https://www pewinternet.org/fact-sheet/mobile/.

125. Pew Research Center. 2019, May 31. Digital Gap Between Rural and Nonrural America Persists Aceessed July 30, 2019. https://www.pewresearch.org/fact-tank/2019/05/31/digital-gapbetween-rural-and-nonrural-america-persists/.

126. Chin et al 2014. Components of the Intervention to Improve Diabetes Care and Outcomes on the South Side. Health Promot Pract. 15:29S-39S

This article is protected by copyright. All rights reserved. 


\section{Figure legends}

Figure 1. Prevalence of Total Diabetes (Diagnosed Diabetes and Undiagnosed Diabetes) in the U.S. Adult Popullation, Ages $\geq 20 y, 2011-2016$. NHW=non-Hispanic White; NHB=non-Hispanic Black; MA=Mexican American; HS=High School education; PIR=Poverty Income Ratio. Source: Unpublished data, National Health and Nutrition Examination Survey.

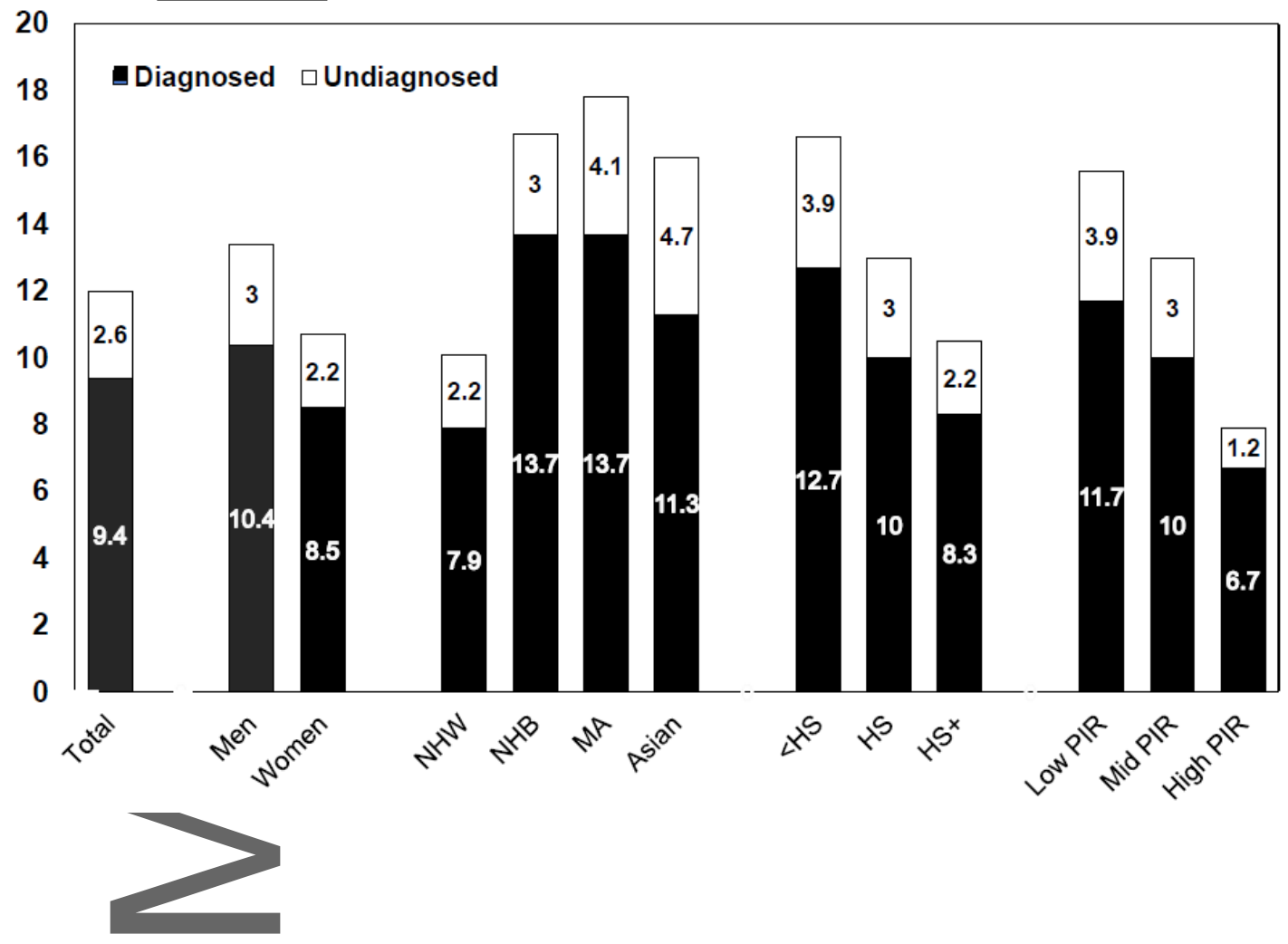

Figure 2. Diagnosed Diabetes (\%): Low (<9.0), Mid (9.0-13.9), High (>13.9); Obesity (\%): Low $(<29.1)$, Mid (29.1-36.0), High ( $>36.0)$. Estimates are percentages at the county-level; natural breaks were used to create categories using 2016 data.

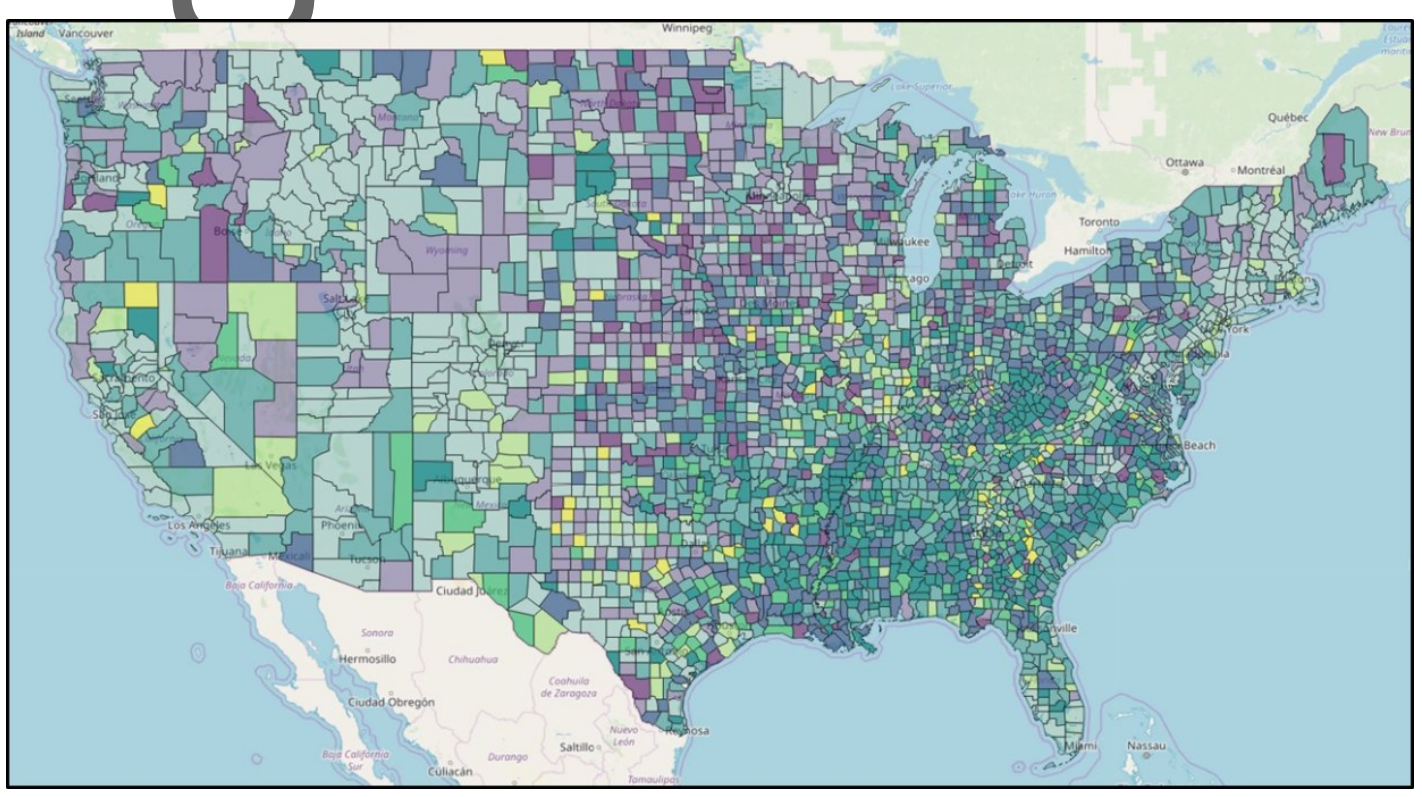

This article is protected by copyright. All rights reserved. 


\begin{tabular}{|c|c|}
\hline Study Designs & $\begin{array}{l}\text { - Novel designs/methods for evaluating multi-level interventions including mixed } \\
\text { methods research } \\
\text { - Study designs other than the traditional RCTs to allow for flexible recruitment } \\
\text { approaches and account for dynamic, pragmatic issues } \\
\text { - Natural experiments to assess the impacts of population-level health programs and } \\
\text { policies } \\
\text { - Life course approaches to understand the interactions of various determinants of health } \\
\text { and influences on disease onset and progression across the lifespan } \\
\text { - Study designs to understand where or how human behavior may overcome the influence } \\
\text { of environmental barriers (i.e., resilience factors) on health } \\
\text { - Cohort studies (existing and new) and new analytic methods to better understand } \\
\text { mechanisms driving obesity and type } 2 \text { diabetes (T2D) disparities } \\
\text { - Engagement of diverse stakeholders (patients, medical staff, community, healthcare } \\
\text { systems) in the full spectrum of science to promote appropriate research questions, } \\
\text { approaches, interpretation and dissemination of findings } \\
\text { - Prospective studies and simulation modeling techniques to increase understanding of } \\
\text { comprehensive environmental change to reduce community-level risk of obesity and } \\
\text { T2D } \\
\text { Approaches to systematically address the pervasive nature of culture in the experience } \\
\text { of illness, in context, and demonstrating the value added by cultural and contextual } \\
\text { adaptations from theoretical and programmatic perspectives }\end{array}$ \\
\hline $\begin{array}{l}\text { Metrics an } \\
\text { Methods }\end{array}$ & $\begin{array}{l}\text { Core metrics of health equity and aspects of built environments and culture that may be } \\
\text { key drivers of outcomes in obesity and T2D } \\
\text { Criteria for establishing novel partnership models in research and assessing } \\
\text { commitment to sustainability of successful interventions beyond grant funding } \\
\text { - Standard methods to examine the effects of socioecological stress on stress reactivity in } \\
\text { various contexts (laboratory experimental, naturalistic settings) } \\
\text { Measures for business case analyses (e.g., alignment of financial incentives and } \\
\text { supports for ongoing organizational investments) }\end{array}$ \\
\hline $\begin{array}{l}\text { Behavioral, } \\
\text { Metabolic, and } \\
\text { Environmental } \\
\text { Phenotyping }\end{array}$ & $\begin{array}{l}\text { Deep environmental and behavioral phenotypes (environment and social factors, } \\
\text { epigenetics, metabolic correlates) to characterize high-risk populations and develop } \\
\text { effective interventions } \\
\text { Multi-level population datasets and systems to characterize elements of society } \\
\text { (housing, education, food resources, activity space, stress levels, etc.) that affect health } \\
\text { equity } \\
\text { - Characterization of specific elements of 'neighborhood deprivation' that influence } \\
\text { diabetes prevention, treatment, and control } \\
\text { Characterization of the unique pathophysiology of T2D among Asian Americans to } \\
\text { facilitate the design of adequately powered studies to evaluate weight control } \\
\text { approaches designed to address this pathophysiology } \\
\text { Phenotypes of specific characteristics within the historically highest risk sub-groups and } \\
\text { the socioecological contexts related to poorer outcomes (e.g., Which African American } \\
\text { men with T2D are at increased risk for amputations?) }\end{array}$ \\
\hline $\begin{array}{l}\text { Considerations } \\
\text { for Stress and } \\
\text { Resilience } \\
\text { Research }\end{array}$ & $\begin{array}{l}\text { - Strategies for preventing the over- and under-treatment of serious mental health } \\
\text { conditions that address realities and perceptions about drug sensitivities, physician bias, } \\
\text { and cultural preferences } \\
\text { - Interactive roles of medications on stress-related disorders (e.g., depression) and } \\
\text { diabetes } \\
\text { - Culturally relevant sources of resilience and coping, and non-traditional interventions } \\
\text { (e.g., mind-body interventions) to improve obesity and T2D outcomes in populations at }\end{array}$ \\
\hline
\end{tabular}

This article is protected by copyright. All rights reserved. 


\begin{tabular}{|c|c|}
\hline & $\begin{array}{l}\text { high risk of various exposures to stress } \\
\text { Evaluation of intervention models to address DNA methylation to reduce risk for } \\
\text { obesity and diabetes } \\
\text { Genetic-based research with sufficient racial/ethnic minority representation to study } \\
\text { diverse characteristics (e.g., histories) and diverse settings to understand gene } \\
\text { expression, stress, and chronic conditions }\end{array}$ \\
\hline $\begin{array}{l}\text { Innovative } \\
\text { Partnership } \\
\text { Models }\end{array}$ & $\begin{array}{l}\text { Biomedical research that is expanded to include the multi-sectoral and multidisciplinary } \\
\text { nature (e.g., economists, architects, urban/regional planners) of built environment and } \\
\text { health research } \\
\text { - Novel partnerships to pursue research questions and designs relevant for diverse groups } \\
\text { and health equity } \\
\text { - Strategies for testing and supporting sustainable partnerships and collaboration practices }\end{array}$ \\
\hline $\begin{array}{l}\text { Intervention } \\
\text { Approach and } \\
\text { Delivery }\end{array}$ & $\begin{array}{l}\text { Multi-sectoral (e.g., academic institutions, government, community organization, public } \\
\text { health entities) partnerships and designs to test the effectiveness of intervening on or } \\
\text { compensating for the influence of systemic barriers (SDoH) on health } \\
\text { Linkages of neighborhood-level characteristics, health systems, and outcomes data } \\
\text { Cohort studies with design and planning of frequent, rapid interventions (e.g., cohorts as } \\
\text { platform for interventions) to allow for adaptive trials } \\
\text { Different combinations of intervention delivery in various contexts to include use of } \\
\text { CHWs and peer support, healthcare and social service team members, e-Health, and } \\
\text { community support and mobilization } \\
\text { Remotely delivered interventions with sufficient racial/ethnic minority representation to } \\
\text { allow for reporting research findings by sub-populations } \\
\text { Study designs that allow exploration of how intersections of various identities } \\
\text { (race/ethnicity, gender, income, place, unemployment, low educational attainment, } \\
\text { difficulty with access to care, etc.) influence intervention effectiveness } \\
\text { Effects of routine screening of SDoH in the medical encounter to inform care and/or } \\
\text { facilitate referrals to address unmet health-related social or basic needs, and testing of } \\
\text { different models to address these } \\
\text { Longitudinal studies to capture impacts of scaling-up efficacious obesity interventions } \\
\text { through national and state programs to address unmet health-related social needs } \\
\text { Effective use of technology for interventions in rural areas with incomplete access to } \\
\text { broadband } \\
\text { Patient-centered (i.e., patient/relative/friend/caregiver) communication such as informed } \\
\text { decision-making processes to promote patients' ability to participate equally in medical } \\
\text { decisions and effects on outcomes (QoL, medical choice, maintaining medical } \\
\text { regimen/patient's medical choice; clinician-patient communication) in high-risk } \\
\text { populations } \\
\text { Intervention approaches to improve treatment effect for non-responders and/or those } \\
\text { who are less likely to engage fully in treatment }\end{array}$ \\
\hline $\begin{array}{l}\text { Implementation, } \\
\text { Scalability, and } \\
\text { Sustainability }\end{array}$ & $\begin{array}{l}\text { - Understanding of the "active ingredients" of obesity prevention and treatment programs } \\
\text { that can be delivered efficiently and disseminated broadly at relatively low cost } \\
\text { - Approaches to sustain positive program outcomes after grant funding, including } \\
\text { strategies for scaling-up programs whose initial success may be tied to non-reproducible } \\
\text { features (charismatic leadership, etc.) and adapt them for diverse population groups with } \\
\text { the community } \\
\text { - Ways to support sustainable reimbursement models for CHWs and peer support in } \\
\text { clinical and community contexts } \\
\text { - Implementation issues that prevent adoption, achieved dose, and sustainability of } \\
\text { effective programs } \\
\text { Broad dissemination of the "Screen at } 23 \text { " campaign in Asian American subgroups; and } \\
\text { systematic approaches to estimate risk of overweight and obesity in specific Asian } \\
\text { subgroups }\end{array}$ \\
\hline
\end{tabular}

This article is protected by copyright. All rights reserved. 


\section{Box 1. Promising approaches for medical and social care integration}

The Improving Diabetes Care and Outcomes on the South Side of Chicago program (known as the South Side Diabetes Project) is a multi-site, multi-targeted intervention designed to address the multiple factors that drive diabetes disparities among low-income racial minorities. The University of Chicago research team works with 4 federally qualified health centers (FQHCs), each of which is part of a large network of health centers, an academic internal medicine/primary care practice, and an academic endocrinology/diabetes clinic. The intervention is built on the Chronic Care Model and has 4 key pillars: patient education and empowerment (e.g., culturally tailored skills training in patient/provider communication and shared decision-making), healthcare provider training, quality improvement (QI)/health systems change, and community connections to local resources for diabetes self-management. ${ }^{34,42-54}$ The research team utilized evidence-based strategies to develop the programs, and the intervention has improved patient experience, patient skills and health behaviors, processes within health systems, and diabetes-related health outcomes, including hemoglobin HbAlc, HDL cholesterol, and foot care. ${ }^{43-45,50-54}$

The health system and community components of the intervention integrate to provide seamless support for patients' diabetes management. For example, physicians can write 'prescriptions' for healthy food (with an accompanying voucher or coupon) at a neighborhood Farmer's Market or a participating Walgreens' store. ${ }^{47}$ Once there, patients receive tours of the healthy food items, participate in cooking demonstrations, and are exposed to other hands-on skills training to support healthy lifestyles. Patients who completed the diabetes education classes were more likely to participate in the community-based programs the team has created (e.g., grocery store tours, community exercise programs) than other patients in the health centers. Thus, there may be a greater opportunity to promote sustained behavioral changes among diabetes patients when health system changes (including patient education) are combined with community-based support programs. ${ }^{49}$

The South Side Diabetes program has been able to meet people where they are and provide the education, skills and tools they need when they are ready for it, utilizing the infrastructure of the health system and community to support the process. The project continues to expose patients to the various clinical and community components of the intervention and evaluates long-term outcomes as guided by the project's multi-level/multi-sectoral framework. (See Fig. 1 in Ref. 126).

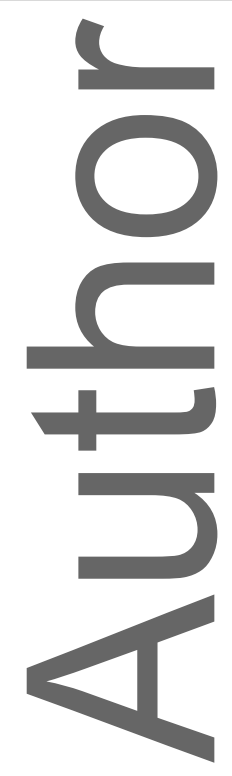

This article is protected by copyright. All rights reserved. 


\section{Box 2. Promising approaches for delivering and scaling-up obesity prevention programs: translations in underserved communities nationwide}

Two studies conducted in St. Louis Missouri, which embedded weight loss counseling based on the principles of the Diabetes Prevention Program (DPP) within a national home visiting program, showed substantial promise for obesity prevention with widespread reach. The home visiting program, Parents as Teachers National Center, Inc. (hereafter referred to as parents as teachers or PAT), trains and coordinates the services of parent-educators who promote early development, learning, and school readiness through ongoing support to families with children from prenatal through kindergarten (https://parentsasteachers.org/). Families can receive up to 25 home visits annually, depending on need. Importantly, PAT uses a resource network to provide comprehensive services to families and children (e.g., unmet basic needs such as housing, food) to ensure optimal early development, health and children's school readiness and success. PAT is located in all 50 states and reaches over 225,000 children annually.

The Healthy Eating and Active Living Taught at Home (HEALTH) Study was designed as a 2-year randomized study to assess the impact of a DPP-derived lifestyle weight loss intervention embedded within the PAT curriculum. ${ }^{121}$ PAT + HEALTH was compared with PAT only (usual care) in a cohort of 179 ethnically and socioeconomically diverse women with overweight or obesity (BMI $\geq 25$ ) and a pre-school child at home. Women in PAT + HEALTH were more likely than those in usual care to achieve $5 \%$ weight loss at 24 months $(11 \%$ vs $26 \%, p=0.01)$, with a $4.7-\mathrm{kg}$ weight difference $(p=0.002)$. Notably, the weight difference between groups was attributed to the intervention group's maintenance of a modest loss of weight versus the control group continuing to gain weight, indicating the value of this strategy for reversing obesity trends by preventing weight gain overtime.

Similarly, the LifeMoms-Washington University Program compared the PAT curriculum to the PAT + Lifestyle intervention, conducted with pregnant and post-partum African American women with overweight or obesity, living with significant socioeconomic disadvantage (e.g., Medicaid recipients or living in low-income neighborhoods, 90 percent reporting household incomes of less than $\$ 25,000$ annually, and approximately half being single parents). By 12 months postpartum, the PAT + Lifestyle group had gained less weight $(2.5 \mathrm{~kg}$ vs. $5.7 \mathrm{~kg} ; P=0.01)$ and were more likely to return to their baseline weight $(38.0 \%$ vs. $21.5 \% ; P=0.01)$ than those receiving the PAT curriculum. ${ }^{122,123}$

The scalability of these embedded lifestyle interventions offers the potential to partner with existing national programs like PAT and leverage infrastructure to reach underserved mothers who have extensive barriers to care for widespread intervention dissemination, reach, and impact.

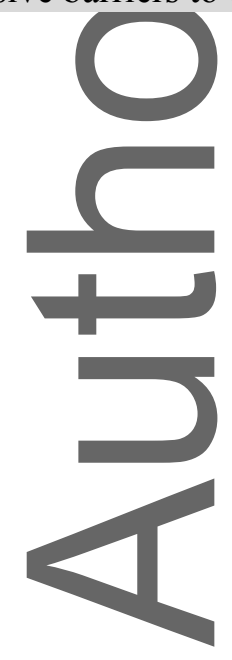

This article is protected by copyright. All rights reserved. 